${ }^{1}$ Federal University of Pernambuco, Recife, Pernambuco, Brazil.
${ }^{*}$ Corresponding author:

Renata Cimões

Email: renata.cimoes@globo.com

Received: November 02, 2020

Accepted: January 12, 2021

\section{Family functioning and dental trauma, malocclusion and anthropometry in adolescents}

\author{
Adelaine Maria de Sousa ${ }^{1}$ (iD, Thais Carine Lisboa \\ Silva ${ }^{1}$ (iD, Bruna de Carvalho Vaigel ${ }^{1}$ (iD, Roberto \\ Carlos Mourão Pinho' ${ }^{1}$, Renata Cimões ${ }^{1, *}$ iD
}

Aim: The aim of the study was to investigate perceived family cohesion and adaptability and its association with trauma, malocclusion and anthropometry in school adolescents. Methods: Cross-sectional study with a representative sample of 921 adolescents from 13 to 19 years old of both sexes, enrolled in state public schools of a northeastern Brazilian municipality. A questionnaire with sociodemographic questions, the FACES III scale was applied and a clinical oral examination (dental trauma and malocclusion) and anthropometric (BMI by age) were performed. For statistical analysis, was evaluated by the Chi-square test. The variables that presented significance in the bivariate analysis of up to $25 \%$ were taken to the multivariate analysis (multinomial logistic regression), variables that presented significance in bivariate analysis of up to $25 \%$ were taken to multivariate analysis and all conclusions were drawn considering the significance level of $5 \%$. Results: As a result, it was identified that displaced families were associated with low maternal education, agglutinated families associated with the absence of caries. Rigid families were associated with marked overjet and caries. The prevalence of dental trauma (37.5\%) was considered high. Conclusion: It was concluded that family cohesion and adaptability were associated with oral health and socioeconomic factors.

Keywords: Oral health. Family. Adolescent. Epidemiology. Holistic health. 


\section{Introduction}

The family plays an important role in the care of its members. This care is characterized by meeting the physical and psychological needs of family members ${ }^{1}$.

Thus, it is valuable to understand the relationship between family members and the degree of union. This makes the functioning of the family an important unit of study and action ${ }^{2}$. This understanding is essential to optimize relationships and improve health conditions and quality of life for family members ${ }^{3}$.

Dental trauma is not the consequence of an illness, but of several factors that occur throughout life ${ }^{4}$. Therefore, investigating factors other than biological ones is of paramount importance, since it is they that influence the lifestyle, the health habits that are taken to the future. And adolescence represents a fundamental moment for health promotion, since it does not always enjoy more of the care and attention one has in childhood 5 . And behavior can be important in the occurrence of dental trauma in adolescents, because aggressive behaviors are risk factors ${ }^{4}$.

A systematic review reveals that dental trauma is one of the most prevalent aggravations in the world and affects people of various ages and social conditions, and that severe overjet is one of the risk factors, traumatic dental injuries have important physical, psychological and economic consequences, with etiological factors varying between countries and age groups ${ }^{6}$, along with socio-demographic, behavioral and overweight factors, The importance of social, economic and structural factors on overweight children's eating patterns and sedentary life style must be considered and this prevention strategy would reduce all types of injuries, diabetes, arteriosclerosis and hypertension ${ }^{7,8}$.

Therefore, this study aimed to investigate the perceived family cohesion and adaptability and its association with dental trauma and other factors such as overjet, anthropometrics and demographics in school adolescents, or that there is no relationship between the variables or phenomena measured.

\section{Materials and Methods}

This study was approved by the Research Ethics Committee of UFPE, under the report number 1,903,021 and in compliance with the ethical requirements and legal criteria of the research

A cross-sectional, analytical and school-based study was conducted in state schools in the municipality of Camaragibe, state of Pernambuco, Brazil, on adolescents regularly enrolled in high school. Camaragibe had 21 state public schools, of which 15 offered high school. Of the 15, 11 accepted to participate.

The municipality has an estimated population of $157,828^{9}$ inhabitants and a state high school network with a total of $4,784^{10}$ adolescents enrolled.

To carry out the sample calculation, the prevalence of 50\% was used, a proportion that maximizes the sample size, as it generates the greatest variance $(p=0.50)(44)$. This means assuming the worst case scenario, that is, for any prevalence the sample is sufficient and significant, with $95 \%$ confidence with an error of $5 \%$. The minimum value for a representative sample was 786 adolescents. To this minimum number was added $20 \%$ to 
compensate for losses, leaving a total of 921 adolescents. In each of the eleven schools, the terms of informed consent were given to the students of the randomly selected classrooms (in each school, three classes were randomly selected, one from each high school grade) to obtain the authorization of those responsible. Those over 18 years of age signed another informed consent form and minors also signed the informed consent form. From the list made available by the Pernambuco Information System, contacts were made for all schools to participate and eleven accepted to participate in the study, offering the lists of the rooms of all high school classes in the morning and afternoon shifts. In each of these

Schools, a draw was made for three classrooms, one class from each grade of high school, in order to make the sample more heterogeneous and representative. All students in the selected class participated, were excluded, in addition to the exclusion criteria, those who refused to participate and / or without authorization from the responsible. Adolescents who did not present the guardian's authorization were excluded.

Adolescents between the ages of 13 and 19, of both sexes were included. Users of orthodontic appliances and adolescents with disabilities that made it impossible to complete the questionnaire or perform the clinical examination were excluded. The adolescents received explanations on how to correctly fill out the forms.

The exams were performed in a school environment by two examiners assisted by note takers. Millimeter probes and odontoscopes were used for the examination of dental trauma and overjet. For anthropometric evaluation, a digital scale and a stadiometer were used. The researchers were calibrated and this process began with a theoretical stage in which the criteria and indexes were presented; followed by clinical exams performed by two examiners and by a more experienced researcher, here considered the gold standard, in twenty adolescents, assisted by note-takers. The calibration process was performed only once The result of the Kappa degree of agreement was above 0.81 for all indexes seen (trauma and overjet). The reasons for dropping out on the part of the adolescents was not wanting to take the clinical exam, even though they answered the questionnaire, especially when checking their weight and height.

The variable dependent on the study was family cohesion and adaptability, collected from the FACES $1{ }^{111}$ scale, validated in Brazil by Falceto and Bozzetti12. For family cohesion, adolescents were divided into three groups. Values below and above the standard deviation corresponded to families with low (disconnected) and high family cohesion (agglutinated), respectively; and values between standard deviations corresponded to families with mean family cohesion (those separated or connected) ${ }^{3}$. For family adaptability, there were also three groups - low (rigid family), moderate (structured or flexible family), and high adaptability (chaotic family), also based on mean and standard deviation.

A questionnaire on socio-demographic data aspects was also applied. In the clinical chart, data concerning the identification of the adolescent, the clinical exams, as well as weight and height for anthropometric calculation were recorded.

Dental trauma was seen through the codes and criteria proposed by García-Godoy ${ }^{13}$ and, for the association test, categorized by absence or presence. The overjet was measured in millimeters and divided into normal ones, those with less than $5 \mathrm{~mm}$, and those with $5 \mathrm{~mm}$ or more were considered accentuated ${ }^{6}$. 
Regarding anthropometric data, weight and height were collected. For the classification, the BMI for the age was used, which is the WHO's and recommended by the Ministry of Health ${ }^{14}$. For this study we divided into two groups, adolescents without overweight (underweight and eutrophic) and those with overweight (overweight, obesity and severe obesity).

The results are presented through the description of absolute and relative frequencies (absolute distribution, percentage and standard deviation of variables). Statistical significance was evaluated by the Chi-square test. The variables that presented significance in the bivariate analysis of up to $25 \%$ were taken to the multivariate analysis (multinomial logistic regression). The bank was made in Epi Info software, with double typing to avoid errors and the analyses were performed in SPSS version 21 and the significance level of $5 \%$ was adopted.

\section{Results}

Of the 921 adolescents, 790 composed the final sample. The majority (93.7\%) were between 15 and 19 years old, with an average age of 16.15 years. Of these, 400 (50.6\%) were female. The most frequent family income was up to 2 minimum wages with $50.5 \%$ of the adolescents and in $59.4 \%$ of the adolescents the mother had more than 9 years of study, that is, they had at least incomplete high school.

The prevalence of dental trauma was 37.5\% and chart 1 shows the distribution of dental trauma according to the tooth and type of fracture.

Chart 1. distribution of dental trauma according to the tooth and type of fracture

\begin{tabular}{|c|c|c|c|c|c|c|c|c|}
\hline \multirow{3}{*}{$\begin{array}{l}\text { Dental } \\
\text { traumatism }\end{array}$} & \multicolumn{8}{|c|}{ Teeth } \\
\hline & DT12 & DT11 & DT21 & DT22 & DT42 & DT41 & DT31 & DT32 \\
\hline & $n(\%)$ & $\mathrm{n}(\%)$ & $n(\%)$ & $\mathrm{n}(\%)$ & $n(\%)$ & $n(\%)$ & $n(\%)$ & $n(\%)$ \\
\hline $\begin{array}{l}0 \text { - no } \\
\text { fracture }\end{array}$ & 767 (97.1) & $672(85.1)$ & $632(80.1)$ & 767 (97.2) & 781 (98.9) & 782 (99.0) & 782 (99.0) & 782 (99.1) \\
\hline $\begin{array}{l}\text { 1- enamel } \\
\text { crack }\end{array}$ & $13(1.6)$ & $61(7.7)$ & $66(8.4)$ & $13(1.6)$ & $5(0.6)$ & $5(0.6)$ & $2(0.3)$ & $1(0.1)$ \\
\hline $\begin{array}{l}2 \text { - enamel } \\
\text { fracture }\end{array}$ & $8(1.0)$ & $48(5.8)$ & $73(9.3)$ & $9(1.1)$ & $4(0.5)$ & $3(0.4)$ & $6(0.8)$ & $5(0.6)$ \\
\hline $\begin{array}{l}3 \text { - enamel } \\
\text { and dentin } \\
\text { fracture }\end{array}$ & $2(0.3)$ & $11(1.4)$ & $18(2.3)$ & $(0.0)$ & $(0.0)$ & $(0.0)$ & $(0.0)$ & $1(0.1)$ \\
\hline Total & 790 (100.0) & $790(100.0)$ & $789(100.0)$ & $789(100.0)$ & $790(100.0)$ & $790(100.0)$ & $790(100.0)$ & $789(100.0)$ \\
\hline
\end{tabular}

Legend :DT 12 - Dental Trauma tooth 12; DT11- Dental Trauma tooth 11; DT21- Dental Trauma tooth 21; DT22Dental Trauma tooth 22; DT42- Dental Trauma tooth 42; DT41- Dental Trauma tooth 41; DT31- Dental Trauma tooth 31; DT32- Dental Trauma tooth 32.

The average for family cohesion was 30.43 with a standard deviation of 5.33 and the average for adaptability was 22.83 with a standard deviation of 3.12 , so families were divided where: $29.4 \%$ had low cohesion, $50.6 \%$ moderate cohesion, $20 \%$ high cohesion, $25.3 \%$ low adaptability, $44.4 \%$ moderate adaptability and $30.3 \%$ high adaptability.

Table 1shows the bivariate analysis in relation to oral, anthropometric and socio-demographic clinical conditions and family cohesion. Only trauma was associated with high cohesion $(p=0.031)$. 
Table 1. Bivariate analysis of family cohesion according to clinical conditions and socio-demographic factors.

\begin{tabular}{|c|c|c|c|c|c|c|c|}
\hline \multirow{3}{*}{$\begin{array}{l}\text { Variables } \\
\text { Low } \\
\mathrm{n}(\%)\end{array}$} & & \multicolumn{4}{|c|}{ Family cohesion } & \multirow{3}{*}{$\begin{array}{c}\text { p-value } \\
\text { (Low x } \\
\text { Medium) }\end{array}$} & \multirow{3}{*}{$\begin{array}{c}\text { p-value } \\
\text { (High x } \\
\text { Medium) }\end{array}$} \\
\hline & & Medium & High & Total & & & \\
\hline & & $\mathrm{n}(\%)$ & $n(\%)$ & $\mathrm{n}(\%)$ & & & \\
\hline \multirow{3}{*}{ Trauma } & No & $144(62.1)$ & $262(65.5)$ & $88(55.7)$ & $494(62.5)$ & 0.386 & $0.031^{\star}$ \\
\hline & Yes & $88(37.9)$ & $138(34.5)$ & $70(44.3)$ & $296(37.5)$ & & \\
\hline & Total & $232(100.0)$ & $400(100.0)$ & $158(100.0)$ & $790(100.0)$ & & \\
\hline \multirow{3}{*}{ BMI } & No Overweight & $162(69.8)$ & 302 (75.5) & $119(75.3)$ & $583(73.8)$ & 0.120 & 0.964 \\
\hline & Overweight & $70(30.2)$ & $98(24.5)$ & $39(24.7)$ & 207 (26.2) & & \\
\hline & Total & $232(100.0)$ & $400(100.0)$ & $158(100.0)$ & $790(100.0)$ & & \\
\hline \multirow{3}{*}{$\begin{array}{l}\text { Maxillary } \\
\text { Overjet }\end{array}$} & Normal & 208 (89.7) & $352(88.0)$ & $139(88.0)$ & $699(88.5)$ & 0.528 & 0.993 \\
\hline & Enlarged & $24(10.3)$ & $48(12.0)$ & $19(12.0)$ & $91(11.5)$ & & \\
\hline & Total & $232(100.0)$ & $400(100.0)$ & $158(100.0)$ & $790(100.0)$ & & \\
\hline \multirow{3}{*}{$\begin{array}{l}\text { Family } \\
\text { Income }\end{array}$} & Up to $2 \mathrm{MW}$ & $123(72.4)$ & $197(65.2)$ & $79(62.2)$ & $399(66.6)$ & 0.112 & 0.550 \\
\hline & Above $2 \mathrm{MW}$ & $47(27.6)$ & $105(34.8)$ & $48(37.8)$ & $200(33.4)$ & & \\
\hline & Total & $170(100.0)$ & $302(100.0)$ & $127(100.0)$ & $599(100.0)$ & & \\
\hline \multirow{3}{*}{$\begin{array}{l}\text { How } \\
\text { many } \\
\text { people } \\
\text { live }\end{array}$} & Up to 2 People & $156(68.1)$ & $272(69.6)$ & $102(65.4)$ & $530(68.3)$ & 0.708 & 0.342 \\
\hline & 3 or more & $73(31.9)$ & $119(30.4)$ & $54(34.6)$ & $246(31.7)$ & & \\
\hline & Total & $229(100.0)$ & $391(100.0)$ & $156(100.0)$ & $776(100.0)$ & & \\
\hline
\end{tabular}

1- Pearson's Chi-square test; *Statistically significant $(p<0.05)$

In table 2 we have the bivariate analysis between oral, anthropometric and sociodemographic clinical conditions and family adaptability, where income of up to two minimum wages $(p=0.030)$ and accentuated overjet $(p=0.002)$ were associated with low adaptability.

Table 2. Bivariate analysis of family adaptability according to clinical conditions and sociodemographic factors.

\begin{tabular}{|c|c|c|c|c|c|c|c|}
\hline \multirow{3}{*}{$\begin{array}{l}\text { Variables } \\
\text { Low } \\
\mathrm{n}(\%)\end{array}$} & & \multicolumn{4}{|c|}{ Family adaptability } & \multirow{3}{*}{$\begin{array}{c}\text { p-value }{ }^{1} \\
(\text { Low x } \\
\text { Medium) }\end{array}$} & \multirow{3}{*}{$\begin{array}{c}\text { p-value }{ }^{1} \\
\text { (High x } \\
\text { Medium) }\end{array}$} \\
\hline & & \multirow{2}{*}{$\begin{array}{c}\text { Medium } \\
\mathrm{n}(\%)\end{array}$} & \multirow{2}{*}{$\begin{array}{l}\text { High } \\
\mathrm{n}(\%)\end{array}$} & \multirow{2}{*}{$\begin{array}{l}\text { Total } \\
\mathrm{n}(\%)\end{array}$} & & & \\
\hline & & & & & & & \\
\hline \multirow{3}{*}{ Trauma } & No & $126(63.0)$ & $221(63.0)$ & $147(61.5)$ & $494(62.5)$ & 0.993 & 0.720 \\
\hline & Yes & $74(37.0)$ & $130(37.0)$ & $92(38.5)$ & $296(37.5)$ & & \\
\hline & Total & $200(100.0)$ & $351(100.0)$ & $239(100.0)$ & $790(100.0)$ & & \\
\hline \multirow{3}{*}{ BMI } & No Overweight & $145(72.5)$ & $253(72.1)$ & $185(77.4)$ & $583(73.8)$ & 0.916 & 0.146 \\
\hline & Overweight & $55(27.5)$ & $98(27.9)$ & $54(22.6)$ & $207(26.2)$ & & \\
\hline & Total & $200(100.0)$ & $351(100.0)$ & $239(100.0)$ & $790(100.0)$ & & \\
\hline \multirow{3}{*}{$\begin{array}{l}\text { Maxillary } \\
\text { Overjet }\end{array}$} & Normal & $165(82.5)$ & 321 (91.5) & $213(89.1)$ & 699 (88.5) & $0.002 *$ & 0.343 \\
\hline & Enlarged & $35(17.5)$ & $30(8.5)$ & $26(10.9)$ & 91 (11.5) & & \\
\hline & Total & $200(100.0)$ & $351(100.0)$ & $239(100.0)$ & $790(100.0)$ & & \\
\hline \multirow{3}{*}{$\begin{array}{l}\text { Family } \\
\text { Income }\end{array}$} & Up to $2 \mathrm{MW}$ & $112(73.2)$ & $162(62.8)$ & $125(66.5)$ & $399(66.6)$ & $0.030 *$ & 0.421 \\
\hline & Above $2 \mathrm{MW}$ & $41(26.8)$ & $96(37.2)$ & $63(33.5)$ & $200(33.4)$ & & \\
\hline & Total & $153(100.0)$ & $258(100.0)$ & $188(100.0)$ & $599(100.0)$ & & \\
\hline \multirow{3}{*}{$\begin{array}{l}\text { How } \\
\text { many } \\
\text { people } \\
\text { live }\end{array}$} & Up to 2 People & $145(73.6)$ & $236(68.4)$ & $149(63.7)$ & $530(68.3)$ & 0.203 & 0.237 \\
\hline & 3 or more & $52(26.4)$ & $109(31.6)$ & $85(36.3)$ & $246(31.7)$ & & \\
\hline & Total & $197(100.0)$ & $345(100.0)$ & $234(100.0)$ & $776(100.0)$ & & \\
\hline
\end{tabular}

1- Pearson's Chi-square test; ${ }^{*}$ Statistically significant $(p<0.05)$ 
After bivariate analysis, using chi-square test, all variables with significance less than 0.25 were included in the Multinominal Logistic Regression model. For cohesion, no variables were associated.

Table 3 reveals that in relation to family adaptability, the multivariate analysis showed that the maxillary overjet $(p=0.010)$ was associated with low adaptability, showing that adolescents with severe overjet are 1.766 times more likely to have low adaptability in relation to average family adaptability.

Table 3. Multivinomial logistic regression for family adaptability

\begin{tabular}{|c|c|c|c|c|c|c|c|c|}
\hline & \multirow{2}{*}{ Variables } & \multirow{2}{*}{ Coef. } & \multirow{2}{*}{ D.E. } & \multirow{2}{*}{$c^{2}$} & \multirow{2}{*}{$\begin{array}{l}\text { Value } \\
\text { of } p\end{array}$} & \multirow{2}{*}{$\mathrm{OR}^{1}$} & \multicolumn{2}{|c|}{$\mathrm{Cl} 95 \%$} \\
\hline & & & & & & & Minimum & Maximum \\
\hline \multirow{2}{*}{ Low } & Constant & -1.064 & 0.336 & 10.035 & 0.002 & & & \\
\hline & Accentuated Overjet & 0.569 & 0.239 & 5.646 & $0.018^{*}$ & 1.766 & 1,105 & 2,823 \\
\hline \multirow{2}{*}{ High } & Constant & -1.061 & 0.343 & 9.580 & 0.002 & & & \\
\hline & Accentuated Overjet & 0.213 & 0.236 & 0.815 & 0.367 & 1.238 & 0,779 & 1,966 \\
\hline \multicolumn{3}{|c|}{ Likelihood Ratio Test (p-value) } & \multicolumn{4}{|c|}{ Goodness-of-Fit Test ( $p$-value) } & \multicolumn{2}{|c|}{$\mathrm{R}^{2}$ of Nagelkerke } \\
\hline \multicolumn{2}{|c|}{15,213} & 0.019 & Pearson & 0.143 & Deviance & 0.107 & \multicolumn{2}{|c|}{0.017} \\
\hline
\end{tabular}

Legend: c2 - chi-square; 1-OR - odds ratio; Cl - confidence interval; Coef- coefficient of the variable; D.E.default error; $\mathrm{R}^{2}$ - coefficient of determination.

\section{Discussion}

There was an association between family cohesion and adaptability with sociodemographic factors and clinical conditions. This result was similar to Ferreira et al. ${ }^{3}$ where it showed that family cohesion perceived by the adolescent was associated with behavioral variables, oral health and socioeconomic factors, another important point was that and increased overjet was associated with adaptability.

The prevalence of dental trauma (37.5\%) was considered high when compared with other studies ${ }^{15-17}$, therefore, early interventions are necessary, in order to reduce the impact of malolusions, and especially overjet on the quality of life and self-esteem of adolescents.

In the present study, a result that, although it did not remain significant in the multivariate analysis, should not be overlooked, is the low income associated with low adaptability. In adolescence, it is important to emphasize that the decision to consult the service is usually made by the parents and not by the youngster himself; furthermore, the socioeconomic condition is one of the most important social determinants in the use of dental services ${ }^{5,18}$. And, therefore, it is important to emphasize that the population studied was of students from public schools, thus being able to be considered homogeneous, economically low; where approximately half has income of up to two minimum wages.

More than half of the adolescents perceived moderate family cohesion and, regarding adaptability, the highest percentage perceived was from families with moderate adaptability. There was an association between severe overjet and low adaptability. Silva and kat $^{19}$, suggest that a family with low adaptability has a low adherence to 
proposed treatments, thus justifying the association between having a more pronounced overjet and having a family with low adaptability.

Low family adaptability was associated to the accentuated overjet Families like this have insufficient adaptive power and, for this reason, would have problems of adherence to treatment protocols ${ }^{19,20}$. This may call attention to the need for new approaches to prevention and health promotion, focusing on family functioning, besides what is already known in the health-disease process.

Overjet is one of the most prevalent types of malocclusion and interferes negatively on the psychological well-being and social interaction of adolescents ${ }^{18}$, besides being a risk factor for dental trauma. However, it is a risk factor that can be altered by the use of orthodontic appliances and can reduce the risk of dental trauma6. Maintaining the oral health of adolescents must also involve education in the oral health of parents and guardians, so the achievement of results in modifying maintenance attitudes or interventions in the oral health of adolescents must involve and reach parents and guardians.

There was no association between BMI and family functioning. A similar result to another study with adolescents in which there was no difference between overweight and eutrophic adolescents with the family relationship, showing that unhealthy family functioning can be common in this phase of life, regardless of nutritional status ${ }^{21}$.

In Brazil, part of the basic care in the public health system is family-centered. This reveals that it should not be limited to clinical issues, but also include family factors in the actions of prevention and health education, promotion and recovery ${ }^{22}$.

Since it is a cross-sectional study, it does not allow a causal relationship, however, this type of design is widely used in health research. And this research is one of the few already carried out involving adolescents' oral health with family functioning ${ }^{3,19}$. And this is important, since it can create guidelines for monitoring the oral health of adolescents at school, as well as family relationships that can contribute to success or failure in both oral health and school performance.

Another result that also deserves attention, despite not remaining significant in the multivariate analysis, is the association between trauma and high cohesion. According to Barber and Buehler ${ }^{23}$, it is possible that families with high cohesion may be more permissive, not establishing rules against, for example, aggressive behavior, which could explain a greater risk for trauma.

Nevertheless, new studies are suggested, with other designs and populations, in order to clarify the involvement of dental trauma and factors associated with it with the family functioning in adolescents.

In conclusion, families with low adaptability, the rigid ones, were associated to the accentuated overjet and there was no association between family cohesion and adaptability with anthropometric data, and the prevalence of dental trauma was considered high and increased overjet was associated with adaptability. 


\section{References}

1. Serapioni M. [The role of $\mathrm{f}$ a $\mathrm{m}$ i ly and pri $\mathrm{m}$ a ry net work in the reform of $\mathrm{s}$ ocial policies]. Cienc Saude Colet. 2005;10(suppl):243-53. Portuguese. doi: 10.1590/S1413-81232005000500025.

2. Olson DH, Sprenkle DH, Russell CS. Circumplex model of marital and family system: I. Cohesion and adaptability dimensions, family types, and clinical applications. Fam Process. 1979 Mar;18(1):3-28. doi: 10.1111/j.1545-5300.1979.00003.x.

3. Ferreira LL, Brandão GAM, Garcia G, Batista MJ, Costa LST, Ambrosano GMB, et al. [Family cohesion associated with oral health, socioeconomic factors and health behavior]. Cienc Saude Colet. 2013;18(8):2461-73. Portuguese. doi: 10.1590/S1413-81232013000800031.

4. Soriano EP, Caldas ADF, Carvalho MVDD, Amorim Filho HDA. Prevalence and risk factors related to traumatic dental injuries in Brazilian schoolchildren. Dent Traumatol. 2007 Aug;23(4):232-40. doi: 10.1111/j.1600-9657.2005.00426.x.

5. Davoglio RS, Aerts DRGC, Abegg C, Feddo SL, Monteiro L. [Factors associated with oral health habits and use of dental services by adolescents]. Cad Saude Publica. 2009;25(3):655-67. Portuguese. doi: 10.1590/S0102-311X2009000300020.

6. Arraj GP, Rossi-Fedele G, Doğramacı EJ. The association of overjet size and traumatic dental injuries-A systematic review and meta- analysis. Dent Traumatol. 2019 Oct;35(4-5):217-32. doi: 10.1111/edt.12481.

7. Glendor U. Aetiology and risk factors related to traumatic dental injuries - a review of the literature. Dent Traumatol. 2009 Feb;25(1):19-31. doi: 10.1111/j.1600-9657.2008.00694.x.

8. Nicolau B, Marcenes W, Sheiham A. Prevalence, causes and correlates of traumatic dental injuries among 13-year-olds in Brazil. Dent Traumatol. 2001 Oct;17(5):213-7. doi: 10.1034/j.16009657.2001.170505.x.

9. Ministry of Planning, Budget and Management of Brazil. Brazilian Institute of Geography and Statistics - IBGE. [2010 Population Census: characteristics of the population and households: results of the universe]. Rio de Janeiro: IBGE; 2011 [cited 2020 Oct 2]. Available from:

https://biblioteca.ibge.gov.br/visualizacao/periodicos/93/cd_2010_caracteristicas_populacao_ domicilios.pdf. Portuguese.

10. Pernambuco State Government Education Information System (SIEPE). Pernambuco 2016 [cited 2020 Oct 2]. Available from:

http://www.siepe.educacao.pe.gov.br. Portuguese.

11. Olson DH. Circumplex Model VII: validation studies and FACES III. Fam Process. 1986 Sep;25(3):33751. doi: 10.1111/j.1545-5300.1986.00337.x.

12. Falceto $O G$ BE, Bozzetti MC. [Validation of diagnostic scales of family functioning for use in primary health care services]. Pan Am J Public Health 2000 Apr;7(4):255-63. Portuguese. doi: 10.1590/ S1020-49892000000400007.

13. García-Godoy FM. Prevalence and distribution of traumatic injuries to the permanent teeth of Dominican children from private schools. Community Dent Oral Epidemiol. 1984 Apr;12(2):136-9. doi: 10.1111/j.1600-0528.1984.tb01426.x.

14. Ministry of Health of Brazil, Department of Health Care, Department of Primary Care. [Guidelines for collection and analysis of anthropometric data in health services: technical standard system of food and nutrition surveillance - SISVAN]. Brasília: Ministry of Health of Brazil; 2011 [cited 2020 Oct 2]. Available from: http://bvsms.saude.gov.br/bvs/publicacoes/orientacoes_coleta_analise_dados_antropometricos.pdf. Portuguese

15. Ministry of Health of Brazil. Health Care Secretariat. Health Surveillance Secretariat. [SB BRAZIL 2010: national research on oral health: main results]. Brasília: Ministry of Health of Brazil; 2012 [cited 2020 Oct 2]. Available from: http://bvsms.saude.gov.br/bvs/publicacoes/pesquisa_nacional_saude_ bucal.pdf. Portuguese. 
16. Vieira EM, Cangussu MCT, Vianna MIP, Cabral MBB, Roque RN, Anjos ES. Prevalência, gravidade e fatores associados ao traumatismo dentário em escolares de 12 e 15-19 anos de idade em Salvador, Bahia. Feira de Santana: Rev. Saúde Col. UEFS; 2017;7(1):51-7.

17. Bendo CB, Paiva SM, Torres CS, Oliveira AC, Goursand D, Pordeus IA, et al. Association between treated/untreated traumatic dental injuries and impact on quality of life of Brazilian schoolchildren. Health Qual Life Outcomes. 2010 Oct 4:8:114. doi: 10.1186/1477-7525-8-114.

18. Martins LP, Bittencourt JM, Bendo CB, Vale MP, Paiva SM. Malocclusion and social vulnerability: a representative study with adolescents from Belo Horizonte, Brazil. Cienc Saude Colet. 2019 Feb;24(2):393-400. doi: 10.1590/1413-81232018242.33082016.

19. Silva JFO, Katz CRT. [Caries experience, treatment needs, and family functioning in Brazilian preschool children: a casecontrol study]. Arq Odontol. 2015;51(2):76-87. Portuguese. doi: 10.7308/ aodontol/2015.51.2.03.

20. Olson DH. Circumplex Model of Marital and Family Systems. J Fam Ther. 2000;22(2):144-67.

21. Almeida CCJN, Mora PO, Oliveira VA, João CA, João CR, Riccio AC, et al. [Variables associated with family breakdown in healthy and obese/ overweigh adolescents]. Rev Paul Pediatr. 2014 Mar;32(1):70-7. Portuguese. doi: 10.1590/S0103-05822014000100012.

22. Department of Primary Care - Secretariat of Health Policies of Brazil. [Family Health Program. Technical Institutional Reports]. Rev Saude Publica. 2000;34(3):316-9. Portuguese. doi: 10.1590/ S0034-89102000000300018.

23. Barber BK, Buehler C. Family cohesion and enmeshment: different constructs, different effects. J Marriage Fam. 1996 May;58(2):433-41. doi: 10.2307/353507. 